\title{
ARTIGOS
}

\section{INVESTIGAÇÕES FENOMENOLÓGICAS SOBRE A PINTURA}

\author{
Eliane Escoubas* \\ el.escoubas@club-internet.fr
}

RESUMO Tenta-se aqui elaborar uma fenomenologia do espaço pictural, com base nos textos de Heidegger, Merleau-Ponty e Henry Maldiney. As análises feitas foram confrontadas in fine com as de historiadores de arte, principalmente Wölfflin.

Palavras-Chave Heidegger, Merleau-Ponty, Maldiney, Wölfflin, Pintura, Espaço,Aaparecer, Ritmo

ABSTRACT This article aims to elaborate a phenomenology of the pictorial space, based on texts by Heidegger, Merleau-Ponty and Henry Maldiney. The analyses made will be compared in fine with the ones art historians produced, in particular Wölfflin's.

Keywords Heidegger, Merleau-Ponty, Maldiney, Wölfflin, Painting, Space, to Appear, Rhythm

Eu teria mesmo uma certa dificuldade para dizer onde é que está o quadro que estou olhando. Pois não o olho como se olha uma coisa, não o fixo em seu lugar; meu olhar vagueia nele como nos nimbos do ser e eu o vejo segundo ele ou com ele, mais do que o vejo. ${ }^{1}$

* Professora do Departamento de Filosofia da Université de Paris XII. Convidada a participar deste número da Kriterion.

1 MERLEAU-PONTY, M. O olho e o espírito. Tradução (um pouco modificada) de Marilena Chauí. São Paulo: Abril Cultural, 1980. p. 90. (N. T.).

KRITERION, Belo Horizonte, $n^{0}$ 112, Dez/2005, p. 163-173 
"Ver segundo" ou "ver com" o quadro: essas expressões marcam a distância entre o simples "ver" e o "ver" na pintura, entre a coisa enquanto coisa e a coisa enquanto quadro. Ou ainda: a distância entre o espaço da percepção ou da representação (o espaço da imagem-cópia ou da imagem-reprodução) e o espaço pictural. Se o "ver segundo" ou o "ver com" são as condições da constituição do quadro como quadro, é precisamente porque o espaço pictural não é um espaço da representação-reprodução do real, que ele não é nem um "depois" (après-coup), nem uma duplicação do real. Mas, então, o que é que a pintura pinta? E o que o espaço do quadro põe à obra?

A resposta resume-se a isto: a pintura pinta as condições da visibilidade segundo a sua modalidade historial e não as condições da reprodução do real. Ou ainda: o espaço do quadro é antes de tudo um espaço do aparecer e da manifestação, e não um espaço da representação. O espaço pictural é o pôrem-obra (mise-en-œuvre) do exercício do olhar, segundo suas modalidades historiais. "Exercício do olhar" diz o pôr-em-movimento do olhar, precisamente seu pôr-em-obra, sua energeia.

Que dizemos quando falamos das "modalidades historiais" do exercício do olhar? O espaço do quadro, o espaço pictural, o espaço "segundo" o qual ou "com" o qual vemos é plural: a história da pintura é testemunha disso. Como não dizer, com efeito, que o espaço da Batalha de São Romão, de Uccello, é diferente do espaço da Ronda da noite, de Rembrandt, ou daquele da Montanha Santa-Vitória, de Cézanne, ou das Casas em L'Estaque, de Braque? Contudo, se se quiser mostrar que a pintura não pinta as condições da reprodução do real, mas as condições da visibilidade segundo sua modalidade historial, não será suficiente estabelecer uma cronologia, isto é, uma história da pintura. Será preciso tentar desdobrar o ser do espaço em jogo a cada vez. Merleau-Ponty mostra-nos o caminho quando escreve: "Essência e existência, imaginário e real, visível e invisível, a pintura embaralha todas as nossas categorias desdobrando seu universo onírico de essências carnais, de semelhanças eficazes, de significações mudas". ${ }^{2}$ Se as categorias que a pintura embaralha estão entre as mais importantes da filosofia, não será preciso dizer que a pintura se inscreve primordialmente numa história da filosofia? Ex-ercício do olhar ex-stase do olhar: o espaço do quadro põe em obra um sentido do ser como aparecer. No espaço do quadro, o fenômeno do mundo (no sentido grego de phainesthai $=$ parecer-aparecer) se expõe mais visivelmente que as coisas localizáveis ou enunciáveis da representação. Isso quer dizer que uma 
análise do espaço pictural depende, por essência, de uma elaboração fenomenológica, enquanto revelação, a cada vez, do alicerce ontológico do ex-ercício do olhar, do ex-stase do olhar.

O que são então os fundamentos ontológicos do espaço pictural?

No § 24 de Sein und Zeit, Heidegger escreve: "O Dasein é espacial". A espacialidade do Dasein humano é um existencial: isto é, uma característica essencial deste ente singular "para o qual se trata em seu ser desse ser", em outras palavras, desse ente cujo "privilégio ôntico consiste no fato de que ele é ontológico". A espacialidade do Dasein só se explicita por oposição à noção cartesiana do espaço: a extensio, enquanto omnimodo divisibile, figurabile et mobile - a extensão homogênea, divisível (partes extra partes) e descritível em termos de "figura e movimento". A espacialidade do Dasein, ao contrário, só pode ser compreendida a partir do seu modo de ser: o modo de ser do Dasein é o ser-no-mundo (In-der-Welt-Sein). É “no-mundo" do ser-no-mundo que se enraízam as características da espacialidade do Dasein. Ora, nos $\S \S 22$, 23 e 24 de Sein und Zeit, o ser-no-mundo do Dasein é antes de tudo ser-nomundo prático (sob o modo da preocupação [Besorgen] e da circunspecção [Umsicht]). A espacialidade do Dasein inscreve-se, pois, numa ontologia pragmática. Ora, o ser-coisa da coisa-pragma está no uso, e a coisa é, de início, utensílio. É somente no seio da ontologia pragmática que podem ser descritos e que adquirem sentido os existenciais da espacialidade do Dasein: o distanciamento (éloignement, Entfernung) e a orientação (Ausrichtung). O distanciamento não é a "distância" que reina na extensão cartesiana; dis-tanciar (é-loigner, ent-fernen), para o Dasein, é des-afastar (ôter le lointain), é aproximar. Do mesmo modo para a orientação, pois, olhando para aí, ouvindo algo aí, indo para aí, o Dasein não está aqui, mas aí (aí onde vê, onde ouve, para onde vai). Ao contrário do Ego cartesiano, que coincide com seu "aqui e agora", o Dasein está fora de si mesmo. Ele está aí, e vem daí, em direção ao seu aqui: a espacialidade do Dasein é, afinal, uma deslocalização — aquilo a que Merleu-Ponty chamará ubiqüidade. Por isso, o Dasein não sobrevoa as distâncias e as direções, ele as traz consigo; eis por que o espaço não é isso dentro do qual ele se encontra, mas isso que ele abre: ele é região (contrée, Gegend). A região é a rede dos dis-tanciamentos e das orientações: desde a ontologia pragmática de Sein und Zeit, a região é um topos.

É ainda a "região" que, para além da ontologia pragmática de 1927, constitui o espaço da arte no texto de 1969: Die Kunst und der Raum. A noção de região é reencontrada aqui sem mudança, se bem que as características que a determinam não sejam mais dis-tanciamento e orientação, mas espaçamento 
(das Räumen) e localização (emplacement, das Einräumen). Assim, desde o início, o espaço terá sido, em Heidegger, não dimensional, mas topológico. "Espaçar" e "localizar" significam "liberar lugares"; ora, um "lugar" é um "ter-lugar" (Geschehen), um "lugar" advém, um lugar não está pré-inscrito no conjunto dos "objetos" do mundo, um lugar não é outra coisa senão o advir do que advém: ele é, em sentido próprio, fenômeno do mundo. No seio dessa espacialidade topológica, definida em termos de acontecimento, a obra de arte tem por propriedade incorporar lugares. Uma ontologia do espaço pictural não tem por noção central a representação-reprodução da voluminosidade, mas a instauração da corporalidade: instauração de "corpos" como acontecimentos.

Tomemos o exemplo do quadro de Jan Van Eyck: A Madona do Chanceler Rolin, onde a tabella plana, regida pela lei da transparência e da voluminosidade, dá a ver três ou quatro planos verticais sucessivos. No primeiro plano, aberto, vêem-se a virgem, o menino e o chanceler doador suntuosamente vestido; no segundo plano, muito reduzido em comparação ao primeiro, um murinho baixo com dois personagens de costas que olham para o terceiro plano. Esse terceiro plano é uma cidade em volta de um rio; e, ao longe, há um quarto plano, de colinas, bastante embaçado. Os quatro planos, cujos objetos, figuras e construções convergem para o mesmo ponto de fuga, se justapõem sem ocultar um ao outro, sem avançar um sobre o outro. Acrescentemos que os personagens que olham para o terceiro plano são como lembrançaou réplica de nós mesmos no ato de olhar o conjunto do quadro. Não serão eles aqui a marca da equivalência abstrata (cartesiana) das partes do quadro? Em outras palavras: será que a perspectiva e a medida proíbem o pôr-em-obra do topos e do acontecimento do "lugar"? Não será preciso, ao contrário, dizer que, aqui, os corpos não são essencialmente "partes" do espaço, mas "lugares"? Pois o quadro dá a ver posturas, e essas posturas são precisamente, na pintura da Renascença, lugares. Elas são "lugares" porque são da ordem do acontecimento. Que espécie de acontecimento? O acontecimento que Van Eyck pinta é o suspense da representação - que é o suspense do tempo enquanto condição necessária para que, na representação, o olhar olhe e a pintura tenha lugar. A pintura tem lugar nesse suspense, antes de tudo ser engolido no ponto de fuga. Em torno do ponto de fuga, como ponto onde se engendra a construção perspectiva, não é apenas nem prioritariamente a extensão do "partes extra partes" que se elabora, mas, antes de tudo, o tempo como modo do aparecer e do desaparecer. Não se pode dizer, então, que o momento epochal (no sentido husserliano do termo), ${ }^{3}$ enquanto momento no qual se deixa a coisa ao seu modo de 
desdobramento, é precisamente aquilo por que o espaço pictural se expõe como fenômeno do mundo, como modo do aparecer? No qual a pintura põe em obra o "como" (das Wie), o eidos, o aspecto — na medida em que o aspecto não é nenhum ente (rien d'étant), mas o parecer do que parece?

Passemos ao exame do Ursprung des Kunstwerkes, de Heidegger: três conferências pronunciadas em 1936. Em busca da "origem" — que não é nem começo cronológico, nem anterioridade causal, vamos descobrir uma circularidade: $o$ artista faz a obra, mas a obra faz o artista. Essa circularidade, se se enuncia aqui como uma fórmula banal, nem por isso deixa de ser o modo pelo qual toda a análise de Heidegger vai funcionar no Ursprung des Kunstwerkes, onde a circularidade vai atuar em várias etapas que constituirão o que Heidegger designa como "o passo atrás". A primeira etapa se interroga para saber se a obra é uma coisa (isto é, em última análise, a conjunção de uma matéria e de uma forma, como o é um utensílio ou um produto); e se a resposta é não, isso não quer dizer que a obra seja uma coisa diferente de uma coisa, que ela deva ser buscada num além da coisa, como "alegoria" — pois, ao contrário, toda divisão "em dois" da obra (forma-conteúdo, sensível-espiritual) é invalidada por Heidegger. Cumpre, pois, buscar a obra em uma "unidade": "é preciso deixar a coisa repousar em si mesma". É então que a obra - por exemplo, um quadro de Van Gogh em que figura um par de sapatos - mostra não outra coisa particular, mas o mundo dessa coisa e o mundo do camponês que usa os sapatos. O quadro se relaciona, pois, com a "eclosão do ente", com o seu desvelamento - Unverborgenheit -, com aquilo que os gregos chamavam alêtheia: verdade como desvelamento. É, pois, a "verdade" como desvelamento que está em obra na obra de arte: a obra de arte é o "pôr-se em obra da verdade". Aqui, pois, a arte não é mais ilustração de alguma coisa, nem embelezamento da existência — não é "cópia" da natureza, nem "alegoria" de uma sobre-natureza, nem manifestação sensível do belo. As diversas possibilidades registradas pela estética tradicional estão invalidadas. O que está em obra na obra de arte é o advento da verdade. Mas de qual verdade? Já se disse: da verdade como "alêtheia". É preciso, pois, enfrentar a questão mesma da essência da verdade: o que é a verdade? É a isso que se aplica a seqüência da investigação heideggeriana, com base no exemplo de um templo grego. $\mathrm{Na}$ estética, encontram-se freqüentemente exemplos tomados de empréstimo à arquitetura, cujo modelo, diz-se, que não é o da natureza. E é mais ou menos o que vai dizer Heidegger: o templo não é à imagem de nada. Mas ele desvela um "mundo" — não um mundo "natural", mas um "mundo historial". O que é um mundo? Não é um simples conjunto de coisas, nem uma moldura para as 
coisas, mas o "sítio" em que o homem existe e que o homem faz existir: reencontramos aqui a necessária circularidade. Um mundo é sempre "historial": feito pelo homem que ele faz, ao mesmo tempo, existir. Esse duplo jogo é o que Heidegger vai identificar com o próprio jogo da verdade - o jogo (circular) do desvelamento e do velamento - e designar como "combate entre mundo e terra": combate entre o desvelamento e o retraimento (retrait). $\mathrm{O}$ afrontamento entre "mundo" (historial) e "terra" (a-historial) é a denominação da tensão imanente à arte, assim como o combate entre o desvelamento e o velamento é imanente à própria verdade: a verdade comporta em sua própria essência a não-verdade (a lathon- léthé). E a essência da verdade coincide com a essência da arte; a beleza, tradicionalmente atribuída à arte, é um dos modos de estadia da verdade como desvelamento (a cidade ou o Estado sendo um outro modo de desvelamento). Assim, a obra de arte não se relaciona com a aisthésis, mas com a alêtheia. Tal é a crítica heideggeriana da estética, que assegura à pintura um estatuto que os fenomenólogos franceses, como Merleau-Ponty e Maldiney, vão desdobrar.

Quando Merleau-Ponty fala de "concentração e vinda a si do visível"4, ele descreve esse momento em que a coisa está liberada a seu modo de desdobramento; ele descreve a instauração do aparecer, enquanto tal, diretamente na pintura. $\mathrm{O}$ que se quer dizer quando se diz que o que a pintura pinta é o aparecer do que aparece, o aparecer enquanto tal? O que se quer dizer senão que o aparecer não é alguma coisa entre as coisas "aparecentes" (apparaissantes)? Que o aparecer é a visibilidade das coisas — sua invisível visibilidade, que só a pintura torna visível? Que a pintura não pinta este visível aqui ou aquele visível acolá (que ela não é a sua reprodução ou representação), mas sim a invisível visibilidade deste visível aqui ou daquele visível acolá? A pintura (toda pintura, mesmo a figurativa) pinta um mundo sem objeto, visto que o mundo que ela faz nascer sob o olhar não tem lugar na objetividade dos objetos, mas na visibilidade enquanto tal — que é o acontecimento de seu aparecer. A pintura faz ver o que não se vê ordinariamente - o que não se vê de todo: ela pinta, a cada vez, o nascimento do mundo sob o olhar - o que sempre já começou quando se começa a ver o que há para ver. "A vinda a si do visível": o visível vindo a si - o que é que isso quer dizer? "A vinda a si do visível" não é outra coisa senão a inseparabilidade do "vidente" e do "visto", o único acontecimento pelo qual ambos advêm. Ela não é outra coisa senão sua reciprocidade - e, portanto, sua reversibilidade: os pintores, diz MerleauPonty, muitas vezes afirmaram que as coisas olhavam para eles. "A vinda a si"

4 MERLEAU-PONTY. O olho e o espírito, p. 96. 
é esta inversão pela qual quem está olhando é olhado e o olhado é quem está olhando; é o entrelaçamento (entrelacs) ou o quiasma (chiasme) do olhanteolhado, cujo lugar é a região. Pintar, então, é ser-olhado por aquilo que se olha.

É precisamente essa "vinda a si", esse mundo no estado nascente - esse mundo sem sujeito nem objeto - que define o espaço pictural e constitui sua diferença relativamente ao espaço científico, técnico ou cotidiano. Eis por que a expressão pela qual Merleau-Ponty qualifica o espaço cézaniano, "o espaço brilha", enuncia o eidos do espaço pictural em geral - a definição inaugural do espaço pictural e sua diferença relativamente a qualquer outro espaço, o espaço técnico, por exemplo. Na pintura, o espaço não se estende, ele brilha. "Brilhar" é o eidos do espaço pictural (seu "aspecto", seu "como"). O único motivo da pintura (quaisquer que sejam suas modalidades historiais) não seria o pôr-em-obra (mise-en-œuvre) do "brilho" do espaço? Onde a coisa está liberada a seu modo de desdobramento, o espaço brilha - e onde o espaço brilha, há espaço pictural, há pintura.

É essa "concentração e vinda a si do visível" no espaço pictural que Henri Maldiney, em Regard, parole, espace, explicita em termos de ritmo: "A arte é a verdade sensível, pois o ritmo é a verdade da aisthêsis". O que é o ritmo? Maldiney define-o nos termos do lingüista Benvéniste: "o ritmo é a forma assumida pelo que é movente, móvel, fluido". O ritmo é, pois, a implicação do tempo no espaço - de "um tempo que não é um tempo de universo, mas um tempo de presença", o tempo próprio àquilo que Maldiney denomina dimensão pática, inobjetiva. Por isso podemos dizer que o ritmo é, ao mesmo tempo, forma e acontecimento. Enquanto forma/acontecimento, o ritmo não tem lugar num espaço: "Ele implica o espaço. Ele abre o espaço". Ele é a articulação do espaço pictural. A noção constitutiva do espaço pictural não é, pois, de modo algum, a noção de "parte", mas a de articulção rítmica. Maldiney mostra que o ritmo tem lugar aquém dos fenômenos físicos. Seus elementos fundadores

não são nem acontecimentos de universo, nem acontecimentos de consciência (...) Nem uma seqüência de sons segundo as leis da física, nem perfis sucessivos de uma mesma coisa ou de um mesmo estado de coisas (...) Tampouco vivências de consciência fazendo parte de um mesmo fluxo individual. Assim, é preciso desfazer-se de uma ilusão teórica, da ilusão teórica que consiste em crer que toda experiência humana é estruturada pela polaridade sujeito-objeto. ${ }^{5}$

A pintura é, pois, a vinda a si do ritmo no espaço — ou antes, o tornar-se ritmo do espaço. E isso transtorna o estatuto da representação na arte. E, 
primeiramente, o estatuto da imagem. A esse respeito, encontramos, em Maldiney, uma fórmula notável: "Na arte, a imagem tem por função não imitar, mas aparecer". Em razão precisamente da ambigüidade da imagem, ele deverá distinguir a "visão estética" da "visão imagificante (imageante)": "A distância que separa a visão imagificante (imageante), a visão por objetos, da visão estética, que se deixa conduzir pelo ritmo das formas ou da luz, mede aquilo a que, de direito, temos de chamar abstração criadora do pintor." Será preciso separar a dimensão formal da dimensão imagificante (imageante) da pintura. Por isso, em L'art, l'éclair de l'être, Maldiney distingue, de um lado, a forma e, de outro, o signo ou a imagem. Signo ou imagem "implicam uma visada intencional que deságua em um momento gnósico", ao passo que a forma, ao contrário, "não é nem intencional nem signitiva" - "significante, todavia, mas, diferentemente do signo, ela implica um momento pático, uma maneira de se portar e de se comportar com relação ao mundo e a si mesmo". ${ }^{7} \mathrm{E}$, de maneira mais precisa ainda: "Uma forma é intransponível em outro espaço, ela instaura o espaço no qual ela tem lugar". ${ }^{8}$ Eis por que Maldiney escreve:

O espaço de Cézanne não é um receptáculo. Seus elementos ou momentos formadores são eles próprios acontecimentos: fragmentações, rupturas, modulações, encontros (...) Surge a Montanha Santa-Vitória. Não há um onde anterior ao seu aparecer, onde se possa dizer que ela tenha lugar. Ela aparece nela mesma, no aberto. Os dois em um só (...) Ela torna visível a invisível dimensão da realidade: o " ẫ" do " tem aî" (le y du il y $a)^{.}{ }^{9}$

Assim, na arte, as formas coincidem com seu ter-lugar: elas coincidem com sua formação e nada mais - elas não são nada, nenhum ente (rien d'étant). Eis por que Maldiney consagrará sua última obra, Ouvrir le rien, l'art nu, à abstração pictural (Kandinsky, Delaunay, Mondrian, Nicolas de Staël, Tal Coat etc.) e mostrará, de maneira soberba, que toda pintura, mesmo figurativa, é "abstrata". Não é sem razão que Maldiney aproxima suas análises das de Oskar Becker sobre "La fragilité du beau et la nature aventurière de l'artiste". Frágil, com efeito, é "o que não se aguardava"; frágil é o inesperado que se torna acontecimento; frágil é a obra de arte pela absoluta descontinuidade do tempo que ela põe em obra. Mas não se trata de acontecimentos parciais e que se poderiam contabilizar; o acontecimento de que se trata na arte é o acontecimento-do-ser — aquilo a que Becker chama Getragenheit (ser-portado),

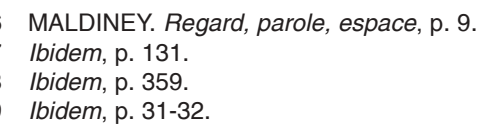


anterior a toda existencialidade e a toda Geworfenheit (ser-lançado), no sentido heideggeriano do termo, assim como a toda intentionalidade, no sentido husserliano.

Na primeira linha de Le surréalisme et la peinture, André Breton escreve: "O olho existe no estado selvagem". Não podemos dizer agora que "o estado selvagem" do olho exprime ao mesmo tempo "a vinda a si do visível", o "ritmo" do aparecer e a "fragilidade do belo" no seio do ser-portado (Getragenheit) em que se enraíza a obra de arte pictural?

Poder-se-ia fazer uma objeção, à primeira vista importante, às investigações fenomenológicas da pintura: poder-se-ia opor a ela uma "história da pintura". Pois há uma pluralidade de tipos, de formas e de modalidades do espaço pictural: há uma história da pintura. Mas olhar um quadro como quadro não é de modo algum considerar um documento que se poderia classificar em uma cronologia e do qual se poderia avaliar as diferenças. Inclassificável e incomparável é o quadro que se olha como quadro. As mutações e rupturas que a história da pintura registra - segundo uma tipologia: espaço renascentista, espaço barroco, espaço impressionista, espaço cubista, espaço abstrato, por exemplo —, ela não faz senão registrá-las, ela não as produz. Tampouco as explica. Pois as mutações do espaço pictural são mutações da "vinda a si do visível". Dito de outra maneira: do ex-ercício e do ex-stase do olhar. Ou ainda: do momento epochal enquanto momento em que a coisa está liberada a seu modo de desdobramento. Todos os espaços picturais são aspectos historiais do ser do ser que não tem uma história, mas que é história. Não nos surpreende que um afresco de Giotto ou um quadro de Uccello possa ainda e sempre pôr o olhar em ex-ercício e em ex-stase; fazer surgir ao olhar a "coisa mesma", o "fenômeno", o aparecer do que aparece.

Os historiadores de arte alemães do início do século XX - conhecidos sob o título de Kunstwissenschaftler - compreenderam-no bem, e essa é a razão por que se pode efetuar uma confrontação frutífera entre suas interpretações e a do conjunto da fenomenologia. Tomemos, por exemplo, a oposição elaborada por Wölfflin entre o espaço clássico (Van Eyck ou da Vinci ou Dürer, entre outros) e o espaço barroco (Rembrandt ou Rubens ou Vermeer, entre outros). Dentre os cinco pares de oposições elaborados por Wölfflin, tomemos o primeiro: a oposição do "linear" e do "pictural" — isto é, a oposição do primado das linhas e do primado das massas. O primado das linhas do espaço clássico está ligado a uma visão que tende à exaustividade, mas também a uma visão horizontal e que tende à fixidez - uma visão que quer simultaneamente provar a exterioridade do visível e limitá-lo, retê-lo: uma visão substancialista. $\mathrm{O}$ primado das massas do espaço barroco está ligado a 
uma visão global, que não vê nada isoladamente, mas vê as superposições (empiètements) e os entrelaçamentos (entrelacs), e também a uma visão vertical (relacionada à queda e à ascensão): uma visão do efêmero e que deve reter o visível nas massas e superposições (empiètements), para impedir seu desaparecimento. Então, não seria preciso dizer que, sob duas modalidades inteiramente diferentes do espaço pictural e da visibilidade, é o eidos do visível que se dá a ver na pintura: é a "vinda a si do visível", enquanto uma fixação substancialista no espaço clássico, e enquanto um aparecer que também é sempre um desaparecer no espaço barroco?

Confrontemos essa oposição elaborada por Wölfflin com a elaborada por Merleau-Ponty, em L'Oeil et l'esprit, entre o espaço propriamente figurativo e o espaço moderno (o qual é, para Merleau-Ponty, ao mesmo tempo o espaço cézaniano e o espaço cubista de Braque ou o espaço abstrato de Klee ou de Nicolas de Staël). Ao espaço figurativo, caracterizado pela divisibilidade e pela exterioridade - o espaço cartesiano do "partes extra partes" —, induzido por uma visão a distância, Merleau-Ponty opõe o espaço cézaniano ou abstrato, que é "um ser de envolvimento", um espaço de inerência e de latência, um espaço do entrelaçamento (entrelacs) e do quiasma (chiasme), no qual a visão não está mais a distância, mas "em contato", cuja propriedade é "fazer rebentar a forma-espetáculo". A "vinda a si do visível" não advém sempre entre a patência (do "linear" wölffliniano) e a latência (do "pictural" wölffliniano)? Qualquer que seja a diversidade de suas modalidades historiais, o espaço pictural não é jamais uma porção de espaço: é um modo do aparecer. Nascimento e surgimento de um mundo sob o olhar — o de um "corpo operante e atual", como escreve Merleau-Ponty ${ }^{10}$ — , eis aí o enigma da pintura.

Tradução: Guido Antônio de Almeida e Virginia Figueiredo

\section{Referências}

BECKER, Oskar. Festschrift Husserl zum 70 Geburtstag gewidmet. Halle: Niemeyer, 1929.

BRETON, André. Le surréalisme et la peinture. Paris: Gallimard, 2000.

DAMISCH, Hubert. L'origine de la perspective. Paris: Flammarion, 1993.

DELEUZE, Gilles. Bacon - Logique de la sensation. Paris: Seuil, 2002.

10 MERLEAU-PONTY. O olho e o espírito, p. 16. 
DERRIDA, Jacques. La verité en peinture. Paris: Flammarion, 1978.

DIDI-HUBERMAN, Georges. Devant l'image. Paris: Minuit, 1990.

. L'image survivante - Histoire de l'art et temps des fantômes selon Aby

Warburg. Paris: Minuit, 2002.

ESCOUBAS, Eliane. Imago Mundi. Paris: Galilée, 1986.

. L'espace pictural. La versanne: Encre Marine, 1995.

. Esthétique. Paris: Ellipses, 2004.

GOETHE, Johann Wolfgang. Zur Farbenlehre, Sämtliche Werke, Bd. 23. Frankfurt am Main: D.K.V., 1991.

GRANEL, Gérard. Sur la couleur de l'expressionisme. In: . Traditionis traditio.

Paris: Gallimard, 1973.

. Lecture de "L'Origine”. In: . Etudes. Paris: Galilée, 1995. . Le monde et son expression. In: . Etudes. Paris: Galilée, 1995.

HAAR, Michel. L'oeuvre d'art, essai d'ontologie des oeuvres. Paris: Hatier, 1994.

HEIDEGGER, Martin. Sein und Zeit. GA 2. Frankfurt am Main: Klostermann, 1977. . Ursprung des Kunstwerkes. Frankfurt am Main: Klostermann, 1980. . Die Kunst und der Raum. St. Gallen: Erker, 1969.

MALDINEY, H. Regard, parole, espace. Paris: L'Age d'homme, 1973. . Art et existence. Paris: Klincksieck, 1985. . L'art, l'éclair de l'être. Paris: Comp'act, 1993.

. Ouvrir le rien, l'art nu. La Versanne: Encre Marine, 2000.

MERLEAU-PONTY, M. Le doute de Cézanne. In: . Sens et non-sens. Paris: Nagel, 1945. . L'œil et l'esprit. Paris: Gallimard, 1960. . Le visible et l'invisible. Paris: Gallimard, 1960.

. O olho e o espírito. Tradução (um pouco modificada) de Marilena Chauí.

São Paulo: 1980.

LA PART DE L'EIL - Revue de l'Académie des Beaux-Arts de Bruxelles. Depuis 1983, particulièrement n. 7 (Art et Phénoménologie) et n. 19-20 (Problème de la Kunstwissenschaft).

LOREAU, Max. La peinture à l'oeuvre et l'énigme du corps. Paris: Gallimard, 1980. MARIN, Louis. Détruire la peinture. Paris: Flammarion, 1997. . Sublime Poussin. Paris: Seuil, 1997.

PODRO, Michaël. Les historiens d'art. Brionne: G. Monfort, 1990.

WÖLLFFLIN, Heinrich. Principes fondamentaux de l'histoire d'art. Brionne: G. Monfort, 1986a. 